\title{
Human synovial sarcoma proto-oncogene Syt is essential for early embryonic development through the regulation of cell migration
}

Taichi Kimura ${ }^{1}$, Mieko Sakai ${ }^{1}$, Kouichi Tabu ${ }^{1}$, Lei Wang ${ }^{1}$, Ryosuke Tsunematsu ${ }^{2}$, Masumi Tsuda ${ }^{3}$, Hirofumi Sawa ${ }^{1, *}$, Kazuo Nagashima ${ }^{1, \dagger}$, Hiroshi Nishihara ${ }^{1}$, Shigetsugu Hatakeyama ${ }^{4}$, Keiko Nakayama ${ }^{5}$, Marc Ladanyi ${ }^{6}$, Shinya Tanaka ${ }^{1}$ and Keiichi I Nakayama ${ }^{2}$

SYT-SSX protein, resulted from chromosomal translocation, causes synovial sarcoma, which is a malignant tumor accounting for $10 \%$ of soft tissue sarcoma. However, biological functions of SYT (synovial sarcoma translocation), also known as SS18, are largely unclear, whereas it has been proven that Syt-null mice die at early stages of embryonic development. Here, we generated Syt-deficient mice and confirmed the reported phenotypes, including growth retardation, open neural tube and haplo-insufficient lethality, and therefore, there is no doubt that Syt is essential for embryonic development. However, placental defects, described in the earlier report, were rarely seen in our mice and we frequently observed cardiac defect in Syt-deficient mice. As the mechanisms responsible for embryonic lethality seem to be complicate, we performed additional experiments. By using primary cultured embryonic fibroblasts, we showed that $\mathrm{Syt}^{-1-}$ MEFs deregulate actin organization and suppressed cell migration. These observations suggest that Syt may contribute to the signaling pathway important for various cellular functions in vivo and in vitro, and we propose that Syt-deficient MEFs would be a powerful means to understand the biological roles of SYT in vitro.

Laboratory Investigation (2009) 89, 645-656; doi:10.1038/labinvest.2009.25; published online 30 March 2009

KEYWORDS: Syt; p300; synovial sarcoma; embryonic lethality; cardiogenesis; motility

Human synovial sarcoma is an aggressive tumor that accounts for almost $10 \%$ of all soft tissue sarcomas and typically arises in the para-articular regions in young adults. ${ }^{1,2}$ Synovial sarcoma possesses a specific chromosomal translocation between chromosomes (chr) 18 and $\mathrm{X}$, forming a chimeric gene fusing SYT (synovial sarcoma translocation) on chr 18 to SSX (synovial sarcoma $\underline{X}$ break point) on chr X. ${ }^{3}$ The translocation found in synovial sarcoma removes the last eight amino acids of SYT and fuses it to the C-terminal portion of the SSX to yield a SYT-SSX fusion protein. ${ }^{3}$ In contrast to SSX, which is thought to act as a transcriptional regulator because of its sequence homology to other tran- scription repressors, SYT does not share a homologous region or conserved domain with other human proteins. ${ }^{4}$

SYT is a ubiquitously expressed nuclear protein containing two distinct domains. One is the SYT amino N-terminal homology domain, which shows homology to the predicted proteins of EST clones derived from a wide variety of species, and the other is the carboxy C-terminal QPGY domain, which is rich in glutamine, proline, glycine and tyrosine. ${ }^{5}$ The QPGY domain was shown to activate the transcription of a reporter gene when it was fused to a DNA-binding domain. ${ }^{5,6}$ As SYT lacks a DNA-binding domain, it may function as a transcriptional co-activator. ${ }^{6}$ In fact, SYT has been shown to

\footnotetext{
'Laboratory of Molecular and Cellular Pathology, Graduate School of Medicine, Hokkaido University, Sapporo, Japan; ${ }^{2}$ Department of Molecular and Cellular Biology, Medical Institute of Bioregulation, Kyushu University, Fukuoka, Fukuoka, Japan; ${ }^{3}$ Department of Laboratory Medicine, Hokkaido University Graduate School of Medicine, Sapporo, Japan; ${ }^{4}$ Department of Molecular Biochemistry, Hokkaido University Graduate School of Medicine, Sapporo, Japan; ${ }^{5}$ Department of Developmental Biology, Center for Translational and Advanced Animal Research on Human Disease, Graduate School of Medicine, Tohoku University, Aobaku, Sendai, Japan and ${ }^{6}$ Department of Pathology, Memorial Sloan-Kettering Cancer Center, New York, NY, USA

Correspondence: Professor S Tanaka, MD, PhD, Laboratory of Molecular and Cellular Pathology, Hokkaido University School of Medicine, N 15, W 7, Kita-ku, Sapporo 060-8638, Japan.

E-mail: tanaka@med.hokudai.ac.jp

${ }^{*}$ Current address: Hirofumi Sawa, Department of Pathobiology, Hokkaido University Zoonosis Research Center, and 21st Century COE Program for Zoonosis Control, N12, W9, Sapporo, Japan

${ }^{\dagger}$ Current address: Kazuo Nagashima, Sapporo Higashi Tokushukai Hospital, N33, E13, Sapporo, Japan
}

Received 25 January 2009; revised 22 February 2009; accepted 27 February 2009 
bind to hBRM/hSNF2 $\alpha$, a major component of the SWI/SNFtype chromatin remodeling complex. ${ }^{5,7-9}$ Moreover, it was also shown that SYT interacts with the putative transcriptional factor AF10, histone acetyl transferase p300 and a component of histone deacetylase complex mSin $3 \mathrm{~A}^{10-12}$ Thus, it is possible that SYT regulates transcription through the binding to chromatin modifiers. In spite of these biochemical studies of SYT, the physiological function of SYT remains largely unknown.

To examine the role of SYT in vivo, we established Syt-deficient mice by a gene targeting strategy. Syt ${ }^{-1-}$ homozygous mutant mice died around mid-gestation and exhibited multiple defects in morphogenesis. These results support the essential gene dosage-sensitive role of Syt in embryogenesis. Subsequently, to examine cellular basis of these phenotypes, we established MEFs from wild-type and $\mathrm{Syt}^{-1-}$ at E9.75. We found that the absence of Syt affects cell migration. These results suggest that SYT plays an important role in cellular motility through the regulation of cytoskeletal organization.

\section{MATERIALS AND METHODS}

\section{Generation of Syt Knockout Mice}

A targeting vector, designed to delete exons 1 and 2 of the Syt gene, was constructed using a PKG-lox-Neo-poly(A) cassette as described earlier. ${ }^{13}$ Briefly, the targeted embryonic stem cell clone was microinjected into host blastocysts, and the resulting chimeric mice were C57BL/6 mice to achieve germ-line transmission of the Syt mutation. The mice used in this study were of mixed genetic background $(129 / \mathrm{Sv}$ and C57BL/6).

\section{Genotyping of Mice}

Genomic DNA samples $(15 \mu \mathrm{g})$ isolated from 3-week-old mice were digested with EcoRV and SpeI and analyzed by Southern blotting. A probe for Southern blotting was generated by genomic PCR. Primer sequences used in this experiment included $5^{\prime}$-TTACAGAGGATTGGGAAAGG- $3^{\prime}$ and $5^{\prime}$-CTGGTATTTCGCTAAGGAAG-3'. Routine genotyping of mice was performed by PCR using three primers: $F 5^{\prime}$-GAG TCC TGC CTG GGA TGA GAA C-3', R 5'-CGA TAG AAG ATG AAG ACT CTG GCC $-3^{\prime}$ and PJL $5^{\prime}$-TGC TAA AGC GCA TGC TCC AGA CTG T-3', which resulted in 453-bp $(\mathrm{F} / \mathrm{R})$ and $370-\mathrm{bp}(\mathrm{F} / \mathrm{PJL})$ products from wild-type and targeted alleles, respectively.

\section{Histopathological and Immunohistochemical Analysis}

Embryos were fixed with 4\% paraformaldehyde in phosphate-buffered saline and embedded in paraffin. Four- $\mu \mathrm{m}$ tissue sections were deparaffinized with xylene and rehydrated through a graded ethanol series and subjected to hematoxylin and eosin stain. Histopathological examination was performed by trained histopathologists. For immunohistochemical analysis, antigens were retrieved in citrate buffer ( $\mathrm{pH}$ 6.0) by using a pressure cooker. Then, sections were incubated with $0.3 \% \mathrm{H}_{2} \mathrm{O}_{2}$ in methanol to quench endogenous peroxidase activity and then treated with normal rabbit or goat serum to eliminate nonspecific binding of the antibodies. After treatment, sections were incubated with primary antibodies for PCNA (M879; DakoCytomation, CA, USA), hBRM (a gift from Yasunori Machida in Nagoya University, Japan), BRG1 (a gift from Yasunori Machida in Nagoya University, Japan) and mSYT (generated in our lab) at $4{ }^{\circ} \mathrm{C}$ overnight. After incubation with the biotinylated secondary antibody, immunoreaction products were visualized with enzymatic reaction of peroxidase, with $3,3^{\prime}$ diaminobenzidine tetrahydrochloride $(\mathrm{DAB})$ as a substrate.

\section{Terminal Deoxynucleotidyltransferase-Mediated dUTP- Biotin Nick End Labeling Assay}

Paraffin-embedded tissue sections were deparaffinized and washed with $0.1 \mathrm{M}$ phosphate buffer for a few minutes, and permeabilized for $20 \mathrm{~min}$ at room temperature (RT) with proteinase $\mathrm{K}(20 \mu \mathrm{g} / \mathrm{ml}$ in $0.1 \mathrm{M}$ phosphate buffer $)$ and bleached with $2 \% \mathrm{H}_{2} \mathrm{O}_{2}$ for $7 \mathrm{~min}$ at RT. Thereafter, the samples were washed with terminal deoxynucleotidyl transferase (TdT) buffer composed of $30 \mathrm{mM}$ Tris- $\mathrm{HCl}$ ( $\mathrm{pH} 7.2$ ), $140 \mathrm{mM}$ sodium cacodylate and $1 \mathrm{mM}$ cobalt chloride, and incubated for $90 \mathrm{~min}$ at $\mathrm{RT}$ with $\mathrm{TdT}$ reaction mixture containing TdT and biotinylated dUTP in TdT buffer. Labeled DNA was visualized with enzymatic reaction of peroxidase and $\mathrm{DAB}$.

\section{Electron Microscopic Analysis}

Embryos were fixed with 2.5\% glutaraldehyde (TAAB; Laboratory Equipment, Aldermaston, UK) in $0.1 \mathrm{M}$ phosphate buffer at $4^{\circ} \mathrm{C}$ for $40 \mathrm{~h}$, and then washed with $7 \%$ sucrose in $0.1 \mathrm{M}$ phosphate buffer. Thereafter, the samples were fixed with $1 \% \mathrm{OsO}_{4}$ (Next Chimica, South Africa) in $0.1 \mathrm{M}$ phosphate buffer at RT for 90 min and gradually dehydrated with 50, 70 and $95 \%$ acetone in ethanol for 15 min each; $95 \%$ acetone for $15 \mathrm{~min}$; and $100 \%$ acetone three times for $20 \mathrm{~min}$ each. Afterward, the samples were treated with epon solution containing $60 \%$ solution A (a mixture of $62 \mathrm{ml}$ of epon 812 (TAAB) and $100 \mathrm{ml}$ of dodecenyl succinic anhydride) and $40 \%$ solution B (a mixture of $100 \mathrm{ml}$ of epon 812 and $89 \mathrm{ml}$ of methyl nadic anhydride). The samples were treated with epon/acetone (1:1) overnight, epon/acetone (3:1) for $1 \mathrm{~h}$ and epon solution for $1 \mathrm{~h}$, and embedded in epon with $1.5 \% 2,4$, 6-tri(dimethylaminomethyl)phenol in a capsule (Nissin EM, Tokyo, Japan). The embedded samples were sectioned on an ultramicrotome at $0.1-\mu \mathrm{m}$ thickness, put onto a grid (TAAB) and treated with $1.5 \%$ uranyl acetate (Merk, Darmstadt, Germany) for $20 \mathrm{~min}$ and $0.2 \%$ lead citrate (Kishida Chemistry, Tokyo, Japan) for $15 \mathrm{~min}$. Finally, the samples were observed with an electron microscope (Hitachi 7100, Tokyo, Japan). 


\section{Immunoblot Analysis}

Immunoblotting was performed according to a standard protocol described elsewhere. ${ }^{14}$ Briefly, embryos were lysed with lysis buffer composed of $50 \mathrm{mM}$ Tris- $\mathrm{HCl}$ ( $\mathrm{pH} 7.6$ ), $150 \mathrm{mM} \mathrm{NaCl}, 0.5 \%$ Triton X-100, $1 \mathrm{mM}$ PMSF and $1 \mathrm{mM}$ $\mathrm{Na}_{3} \mathrm{VO}_{4}$, and clarified by microcentrifugation at $12000 \mathrm{~g}$ for $10 \mathrm{~min}$ at $4^{\circ} \mathrm{C}$. Supernatants containing $20 \mu \mathrm{g}$ of proteins were subjected to SDS-PAGE, and separated proteins were transferred to PVDF filters. The filters were blocked with 5\% skim milk and incubated with primary antibodies for hBRM, BRG1, p300 (N-15; Santa Cruz Biotechnology, CA, USA), mSYT and $\alpha$-tubulin (B-5-1-2; Sigma, MI, USA). Antibody binding was visualized by chemiluminescence (ELC; Amersham Pharmacia Biotech, NJ, USA).

\section{RNA Extraction, Labeling and Hybridization}

For microarray analysis, RNA was isolated from embryos or MEFs using the RNeasy mini kit (Qiagen, CA, USA). For microarray studies, labeling and hybridization were performed according to Affymetrix standard protocols. Labeled cRNA was hybridized onto the Affymetrix GeneChip Mouse Genome 430A 2.0 array (Affymetrix, CA, USA), which contains 22691 probes. Microarray slides were scanned using the Affymetrix GCS 2500 scanner to collect fluorescence signal.

\section{Preparation of MEFs and Cell Cultures}

Primary MEFs were obtained from 9.75 d.p.c. embryos that were either wild-type or $\mathrm{Syt}^{-/-}$using established procedure. ${ }^{15}$ Cells were cultured at $37^{\circ} \mathrm{C}\left(6 \% \mathrm{CO}_{2}\right)$ in $\mathrm{MEF}$ medium (Dulbecco's modified Eagle's medium containing $10 \%$ fetal bovine serum supplemented with $2 \mathrm{mM}$ L-glutamine, $0.1 \mathrm{mM}$ sodium pyruvate, $0.1 \mathrm{mM}$ MEM nonessential amino-acid solution, $100 \mathrm{U} / \mathrm{ml}$ penicillin G, $100 \mu \mathrm{g} / \mathrm{ml}$ streptomycin and $50 \mu \mathrm{M}$ 2-mercaptoethanol).

\section{Immunocytofluorescence and Confocal Microscopy}

Wild-type and Syt ${ }^{-1-}$ MEFs were grown on Lab-Tek chamber slides (Nalge Nunc, NY, USA) in MEF medium, were fixed with 3\% paraformaldehyde in PBS for $15 \mathrm{~min}$, permeabilized with $0.5 \%$ Triton X-100 in PBS for 5 min and incubated with $1 \%$ bovine serum albumin in PBS for $20 \mathrm{~min}$ at RT. They were then incubated overnight at $4{ }^{\circ} \mathrm{C}$ with mouse monoclonal antibodies specific for paxillin (1:2000; BD Transduction Laboratories, CA, USA), then for $1 \mathrm{~h}$ at RT with Alexa Fluor 488-conjugated secondary antibodies (Molecular Probes, OR, USA) and finally for $30 \mathrm{~min}$ at RT with Alexa Fluor 594-conjugated phalloidin (Molecular Probes). The cells were then examined with a confocal laser-scanning microscope equipped with a computer (MRC-1024; Bio-Rad Microscience, CA, USA).

\section{Wound Closure Assay}

The wound closure assay was performed as described. ${ }^{16}$ Wild-type and Syt ${ }^{-1-}$ MEFs were grown in MEF medium for $48 \mathrm{~h}$. The confluent cells were wounded by scratching the monolayer with a pipette tip, washed twice with PBS, allowed to migrate in MEF medium for the indicated times and photographed. The assay was performed in triplicate.

\section{Semi-Quantitative Reverse Transcription PCR Analysis}

Total RNA was isolated from wild-type and Syt $^{-1-}$ MEFs using RNeasy mini kit (Qiagen) according to the manufacturer's instruction. Reverse transcription was carried out with Superscript II RT (Invitrogen, CA, USA) according to the manufacturer's instruction. One hundred nanograms of the resulting first-strand cDNA was used as template and amplified by PCR using KOD-Plus DNA polymerase (Toyobo, Osaka, Japan). Sequences of the oligonucleotide primer sets used for reverse transcription PCR (RT-PCR) analysis are as follows: CD44: forward 5'-GCA CCC CAG AAG GCT ACA TTT- $3^{\prime}$, reverse $5^{\prime}$-TCT GCC CAC ACC TTC TCC TAC TAT3'; FoxG1: forward 5'-CAG CAC TTT GAG TTA CAA CG-3', reverse $5^{\prime}$-TGG TCT GCG AAG TCA TTG AC-3'; HMGA2: forward $5^{\prime}$-AAC CTT ACT GGG TCG GCA TC- $3^{\prime}$, reverse $5^{\prime}$ GGT GAG GTT TGA GCT CCT TC-3'; IGFR2: forward 5'CAG GTA GCG AAA AGT GGT AAG T- $3^{\prime}$, reverse $5^{\prime}$-GCC TGG TCT GTT TCT GTG ATT G-3'; Neuropilin: forward 5'-GAA TGT TGG GCA TGG TGT CT- $3^{\prime}$; reverse $5^{\prime}$-CTT AGCCTTGCGCTTGCT- $3^{\prime}$; Neurotrophin3: forward 5'-AAA ACC GGT AAC TCT CCT GTG- ${ }^{\prime}$, reverse $5^{\prime}$-CTA CGA GTT TGT TGT TTT CTG- $3^{\prime}$, PDGFRB: forward $5^{\prime}$-AGG TCA TTG AGT CTG TGA GC- $3^{\prime}$, reverse $5^{\prime}$-ATC GGC AGT ATT CCG TGA TG-3'; Pleiotrophin: forward 5'-ACT GGC GCC GAG TGC AAACAG- $3^{\prime}$, reverse $5^{\prime}$-GAG CTT GCC ACA GGG CTT GGA-3'; RGEF4: forward 5'-GCC TAT TCG TGG CTC TG-3', reverse 5'-CAGACCTCAGTGACAACC-3'; RUNX2: forward 5'-CTC TGG CCT TCC TCT CTC AGT AA-3', reverse 5'-TAG GTA AAG GTG GCT GGG TAG TG-3'; SDF1: forward $5^{\prime}$-ACT TTC CCT CTC GGT CCA C-3', reverse 5'-TTG TTT AAA GCT TTC TCC AGG TA-3'; TCF-4: forward $5^{\prime}$-GGG GCT CAT ACT CAT CTT-3' ${ }^{\prime}$, reverse $5^{\prime}$-GCC TGT CCT CCA TTT CTA-3'; GAPDH: forward 5'-GTC GTG GAG TCT ACT GGT GTC-3' ${ }^{\prime}$, reverse $5^{\prime}$-GAG CCC TTC CAC AAT GCC AAA-3'.

\section{RESULTS}

\section{Generation of Syt-Deficient Mice}

A targeting vector containing a Neo cassette was used to replace the $5.2-\mathrm{kb}$ genomic sequence of Syt gene including exon land exon 2 through homologous recombination (Figure 1a). Southern blot analysis using tail DNA from 3 -week-old mice confirmed that Syt ${ }^{+/-}$mouse carried targeted allele (Figure 1b). Targeting of the Syt gene was also confirmed by immunohistochemistry and immunoblotting using E10.5 mouse embryos (Figure 1c and d). Heterozygous embryos seemed to express less amount of Syt protein than wild-type embryos (Figure 1d).

To date, none of the Syt ${ }^{-1-}$ homozygous mutant has been detected among the 202 newborns from heterozygote crosses. Syt $^{+/-}$heterozygous offspring appeared to be normal and 
a
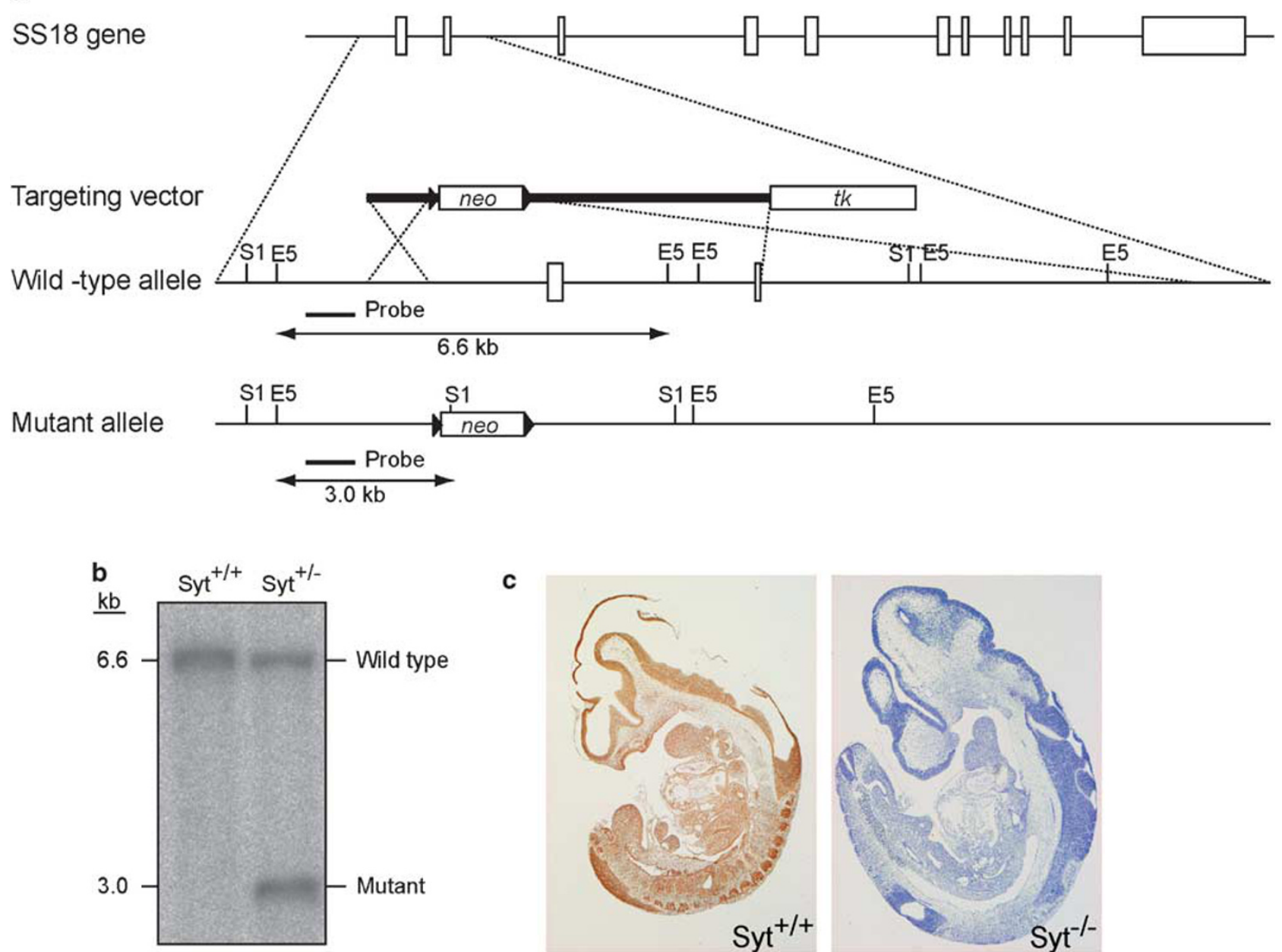

C
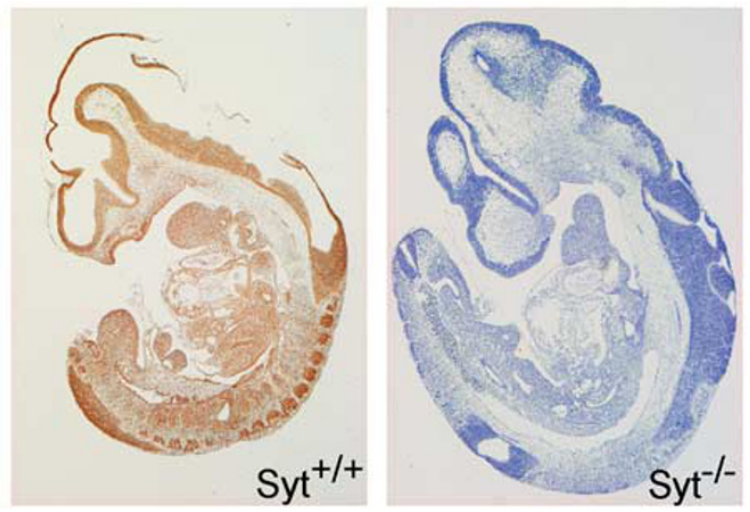

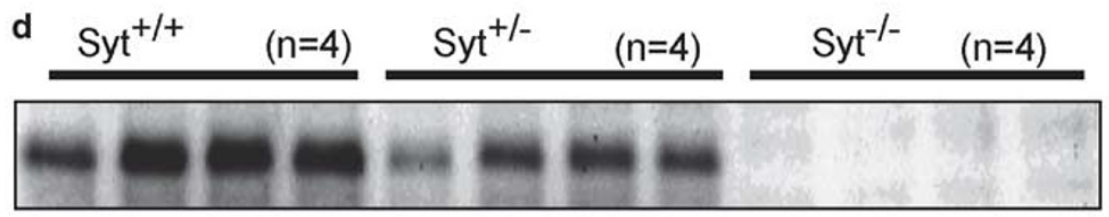

mSYT

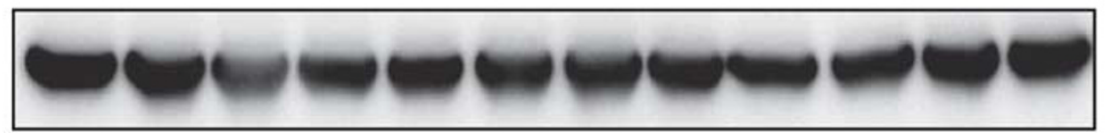

$\alpha$-Tubulin

Figure 1 Targeting disruption of the Syt locus and the establishment of a mutant mouse strain. (a) Schematic representation of the wild-type allele, targeting vector and targeted allele. The open boxes on the alleles represent the exons. A Neo cassette replaced exons 1 and 2 of the Syt gene. The expected sizes of the EcoRV (E5) and Spel (S1) digestion products of the gene, hybridized with the indicated probe, are shown. (b) Genomic DNA isolated from 3-week-old mice was digested with EcoRV and Spel, and analyzed by Southern blotting with the probe shown in (a). (c) Wild-type (left) and homozygous (right) E10.5 embryos were subjected to immunohistochemistry using an anti-mSYT antibody. (d) Protein extracts (30 $\mu \mathrm{g}$ ) from wild-type (lanes 1-4), heterozygous (lanes 5-8) and homozygous E10.5 embryos (lanes 9-12) were analyzed by immunoblotting using an anti-mSYT antibody.

fertile. The rate of Syt ${ }^{+/-}$heterozygous mutants among newborns was $38 \%$ lower than that expected by Mendelian inheritance (Table 1). As no neonatal lethality was observed, a certain population of Syt ${ }^{+/-}$heterozygous embryos must have died very early in utero.

\section{Histopathological Examination of Syt-Deficient Mice}

To determine the time point at which the Syt ${ }^{-1-}$ mutant embryos become lethal, we examined embryos from Syt ${ }^{+/-}$ intercrosses at various developmental stages. Most of Syt ${ }^{-1-}$ homozygous embryos were alive at E9.5. At E10.5, approxi- 
Table 1 Genotype of embryos from Syt heterozygous intercrosses

\begin{tabular}{lrrcr} 
Embryonic & \multicolumn{3}{c}{ Numbers of analyzed mice } \\
\cline { 2 - 4 } day & $+/+$ & $+/-$ & $-/-\left(\right.$ abnormal $\left.{ }^{\mathrm{a}}\right)$ & Total \\
\hline E7.5 & 8 & 4 & $5(0)$ & 17 \\
E8.5 & 6 & 8 & $5(0)$ & 27 \\
E9.5 & 202 & 411 & $190(30)$ & 803 \\
E10.5 & 118 & 229 & $105(51)$ & 452 \\
E11.5 & 25 & 60 & $21(17)$ & 106 \\
E13.5 & 12 & 16 & $1(1)$ & 29 \\
New born & 90 & 112 & $0(0)$ & 202 \\
\hline
\end{tabular}

${ }^{\mathrm{a}}$ The number of embryos with a macroscopic abnormality is indicated in parentheses.

mately $50 \%$ of $\mathrm{Syt}^{-1-}$ embryos were already dead as judged by heartbeats or the signs of re-absorption, and no Syt ${ }^{-l-}$ homozygous mutants could be retrieved after E11.5 (Table 1). The Syt ${ }^{-1-}$ embryos dissected at E9.75 were developmentally retarded in size (Figure $2 \mathrm{a}$ and $\mathrm{b}$ ). The most severely affected but still viable mutant embryos usually displayed little or no signs of embryonic turning and exhibited only 10-14 somites (Figure 2c). We determined that the developmental arrest of Syt ${ }^{-/-}$embryos began at E8.5-E9.0, because generally, embryonic turning starts at E8.5 (8 somites) and is completed around E9.0 (16 somites).

Morphologically, all $\mathrm{Syt}^{-1-}$ embryos could be distinguished from their wild-type littermates as early as E9.5 by their severe open neural tube as the neural tube begins to close at E8.5 and is completed by E9.0. These also suggest that developmental arrest of Syt ${ }^{-1-}$ embryos was caused at E8.5E9.0. In addition, various degrees of exencephaly were observed in Syt ${ }^{-1-}$ embryos. Typically, the neural tube failed to fuse at the hindbrain and forebrain (Figure $2 b$ and $c$ ). In the most severely affected mutants (data not shown), it remained completely open. Histological examination of E10.5 embryos revealed the exencephaly was caused by failure of neural tube closure (compare Figure $2 \mathrm{~d}$ and e). The heterogeneity in the severity of Syt mutants indicates a partial penetration of the phenotypes possibly due to the genetic modifiers.

To identify the downregulated genes that are related to the phenotypes of $\mathrm{Syt}^{-1-}$ mutants, we performed Gene Chip analysis using wild-type and $\mathrm{Syt}^{-1-}$ embryos at E9.75. Many genes related to embryonic growth or neuronal development were downregulated in $\mathrm{Syt}^{-1-}$ mutants (Supplementary Table 1).

As neural tube defects generally do not cause early embryonic lethality, we examined other developmental abnormalities in Syt ${ }^{-1-}$ mutant embryos. While this study was in progress, another group reported the establishment of Sytdeficient mice, ${ }^{17}$ exhibiting embryonic lethality between E8.5 and E9.5 either through an incomplete chorio-allantoic fusion or through a defect in the subsequent process of vascular branching morphogenesis. ${ }^{17}$

In contrast to the above-mentioned Syt ${ }^{-/-}$mice, almost all of our $\mathrm{Syt}^{-1-}$ mutant embryos displayed normal chorioallantoic fusion and exhibited normal labyrinth formation consisting of placental and embryonic vasculature at E9.75 (Figure 2f-k), even though their developmental stages were somewhat retarded. Thus, the embryonic lethality may not be due to the placental defect in our Syt ${ }^{-1-}$ mutant embryos.

As placental defects did not provoke early embryonic lethality, at least before E9.5, we extensively examined other developmental abnormalities in our Syt ${ }^{-1-}$ mutant embryos. At E9.5-E10.5, a number of Syt ${ }^{-1-}$ mutants showed an enlarged cardiac cavity. Furthermore, Syt ${ }^{-1-}$ mutants displayed severe pericardial effusions (Figure 2c), one of the clear signs of cardiac dysfunction. Cardiac ventricular movements appeared to be weaker and less expansive in mutants compared with that in wild-type embryos. Although no overt patterning defect was observed, the ventricular chambers of mutant embryos exhibited significantly thin wall and retarded maturation of trabeculation (Figures $2 \mathrm{l}-\mathrm{o}, 4 \mathrm{a}$ and $\mathrm{b}$ ).

\section{Immunohistochemical Analysis of Syt-Deficient Mice}

As the cardiac defect was found in $\mathrm{Syt}^{-1-}$ embryos, we examined Gene Chip data of whole embryos focusing on cardiogenesis-specific genes. However, an obvious downregulation of cardiogenesis-specific genes was not observed in Syt $^{-/-}$mutants (Supplementary Table 2).

Therefore, for better understanding the basis for the cardiac abnormality in the Syt ${ }^{-1-}$ mutants, we analyzed whether cardiomyocytes undergo apoptosis by terminal deoxynucleotidyltransferase-mediated dUTP-biotin nick end labeling assay. In both wild-type and $\mathrm{Syt}^{-1-}$ embryos, no significant induction of apoptosis was observed in various tissues (Figure $3 \mathrm{a}-\mathrm{d}$ ). Cell growth rates were also analyzed by immunostaining using antibodies for proliferation marker proteins, such as Ki-67 antigen and PCNA. The labeling indices of Ki-67 in the neural tube of wild-type embryos were higher than those in $\mathrm{Syt}^{-/-}$embryos at E10.5 (Figure 3e-h). In addition, immunostaining for PCNA showed that the growth rates of cardiomyocytes in $\mathrm{Syt}^{-/-}$embryos were much lower than those in wild-type embryos (Figure 3i-1). These results suggest that decreased cell growth may contribute to the impaired formation of cardiac ventricle in Syt $^{-1-}$ embryos.

Ultrastructural Analysis of the Heart in Syt ${ }^{-1-}$ Embryos For further analysis, we employed electron microscopy. First, we carefully prepared specimens from comparable areas of the ventricular free wall in both wild-type and $\mathrm{Syt}^{-1-} \mathrm{em}$ bryos (Figure $4 \mathrm{a}$ and $\mathrm{b}$ ). After, we confirmed the abnormality of the ventricular walls by toluidine blue staining, then the corresponding areas were subjected to electron microscopy. In cardiomyocytes of Syt ${ }^{-1-}$ embryos at E10.5, the numbers 

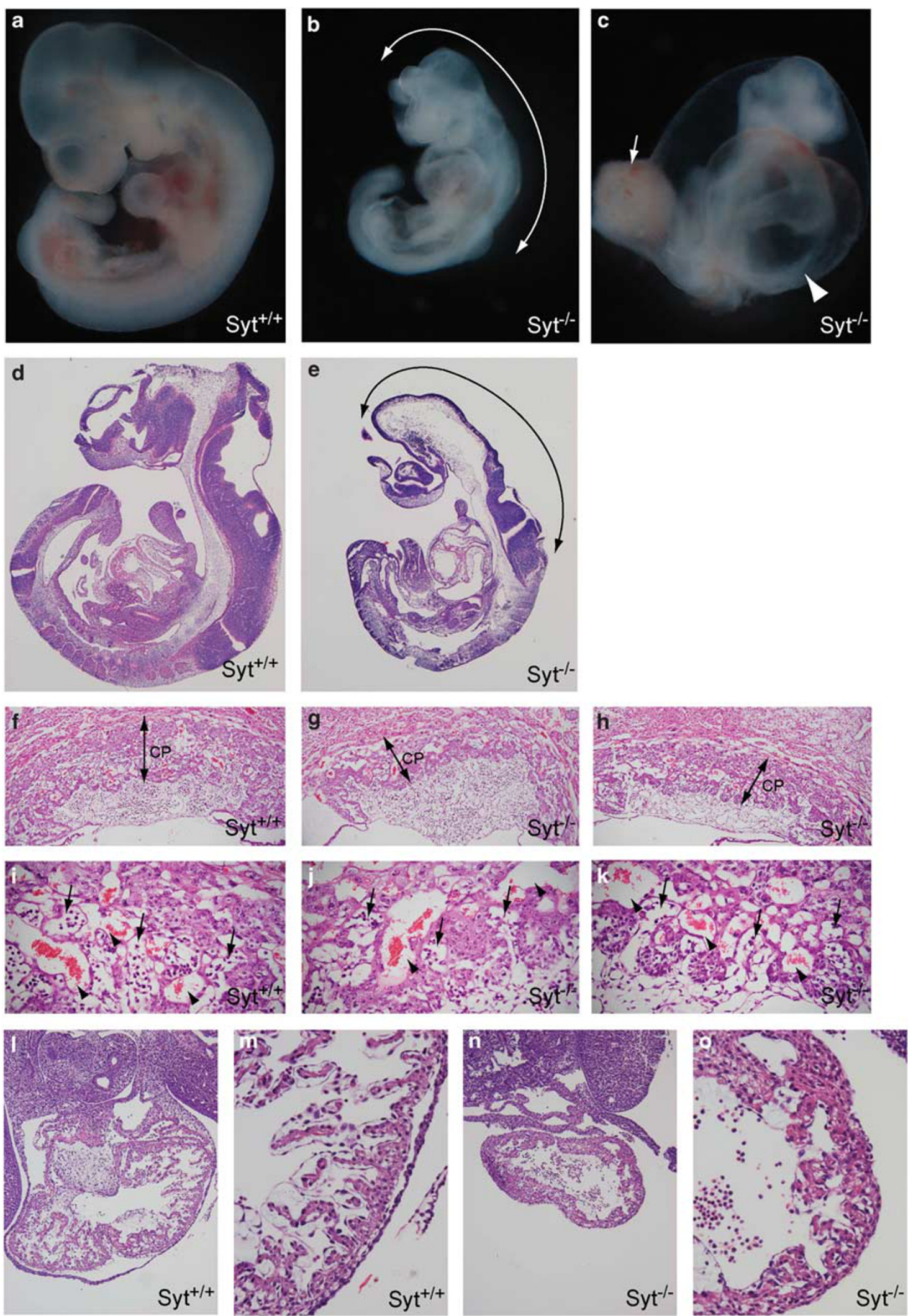
of perinuclear myofibrils and also of myofibrillar bundles were decreased (Figure $4 \mathrm{c}$ and d). Sarcomeric structure showed no significant difference between wild-type and Syt ${ }^{-1-}$ mutant embryos (Figure 4e and f). Thus, cardiac development was perturbed in $\mathrm{Syt}^{-1-}$ embryos, and this may be responsible for embryonic lethality.

\section{Downregulation of p300 Expression in Syt-Deficient Mice}

All Syt $^{-1-}$ homozygous mutants displayed lethality by E11.5, and among published gene knockout mice, especially those targeting chromatin modifiers, the phenotypes of $\mathrm{Syt}^{-1-}$ mutants closely resembled those of p300-deficient mice. ${ }^{18}$

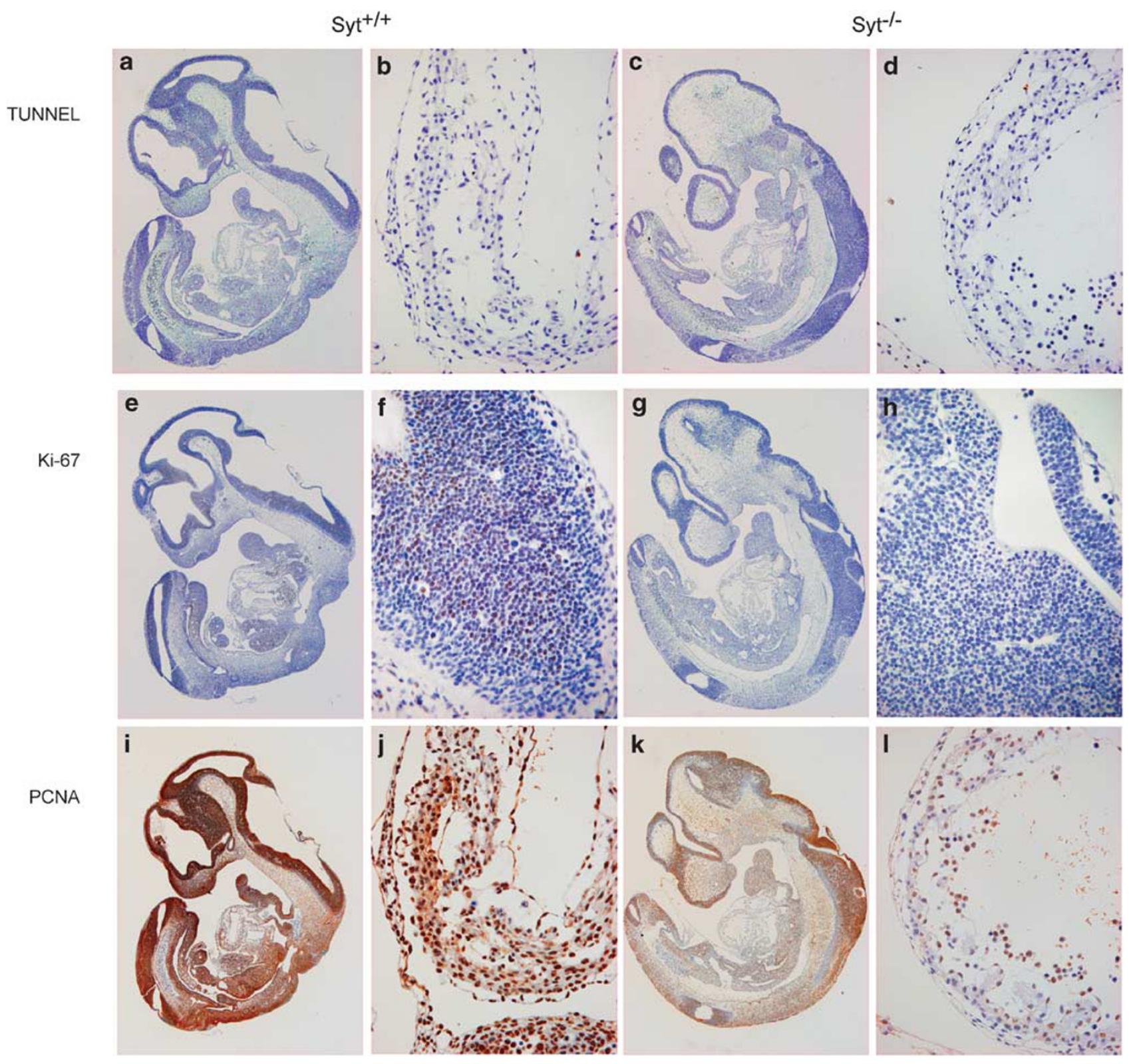

Figure 3 Immunohistochemical analysis for apoptosis and cell growth. (a-d) TUNEL staining; (e-h) immunostain for Ki-67 and (i-I) PCNA. Syt ${ }^{+/+}(\mathbf{a}, \mathbf{b}, \mathbf{e}, \mathbf{f}$, $\mathbf{i}$ and $\mathbf{j})$ and $\operatorname{Syt}^{+/-}(\mathbf{c}, \mathbf{d}, \mathbf{g}, \mathbf{h}, \mathbf{k}$ and $\mathbf{I})$ are indicated. Magnification $\times 20(\mathbf{a}, \mathbf{c}, \mathbf{e}, \mathbf{g}, \mathbf{i}$ and $\mathbf{k})$ and $\times 400(\mathbf{b}, \mathbf{d}, \mathbf{f}, \mathbf{h}, \mathbf{j}$ and $\mathbf{I})$.

Figure 2 Morphological analyses of Syt homozygous mutant embryos. (a-c) Representative stereoscopical appearance of embryos at E9.75 Syt $+/+(\mathbf{a})$ and $\mathrm{Syt}^{-1-}$ (b and $\mathbf{c}$ ). Double-headed arrow in panel b indicates open neural tube. Arrowheads in panel $\mathrm{c}$ indicate pericardial edema and arrow in panel $\mathrm{c}$ indicates allantois. (d-o) Microscopic analysis by H\&E stain. Sagittal section of Syt $+/+(\mathbf{d})$ and Syt $^{-1-}(\mathbf{e})$ embryos at E10.5. Double-headed arrow in panel e indicates open neural tube. (f-k) Histopathology of Syt ${ }^{+/+}$(f and $\left.\mathbf{i}\right)$ and $\mathrm{Syt}^{-/-}(\mathbf{g}, \mathbf{h}, \mathbf{j}$ and $\mathbf{k}$ ) developing placenta at E9.75 (i, $\mathbf{j}$ and $\mathbf{k}$, higher magnification of $\mathbf{f}, \mathbf{g}$ and $\mathbf{h}$, respectively). Double-headed arrows and CP in panels $\mathbf{f}-\mathbf{h}$ indicate chorionic plate. Arrows in panels i-k indicate embryonic blood vessels, and arrowheads in panels i-k indicate maternal blood vessels, respectively. (I-o) Histopathology of Syt $+/+(\mathbf{I}$ and $\mathbf{m})$ and Syt ${ }^{-1-}$ (n and o) embryonic heart at E10.5 ( $\mathbf{m}$, transverse section and $\mathbf{o}$, higher magnification of $\mathbf{I}$ and $\mathbf{n}$, respectively). 

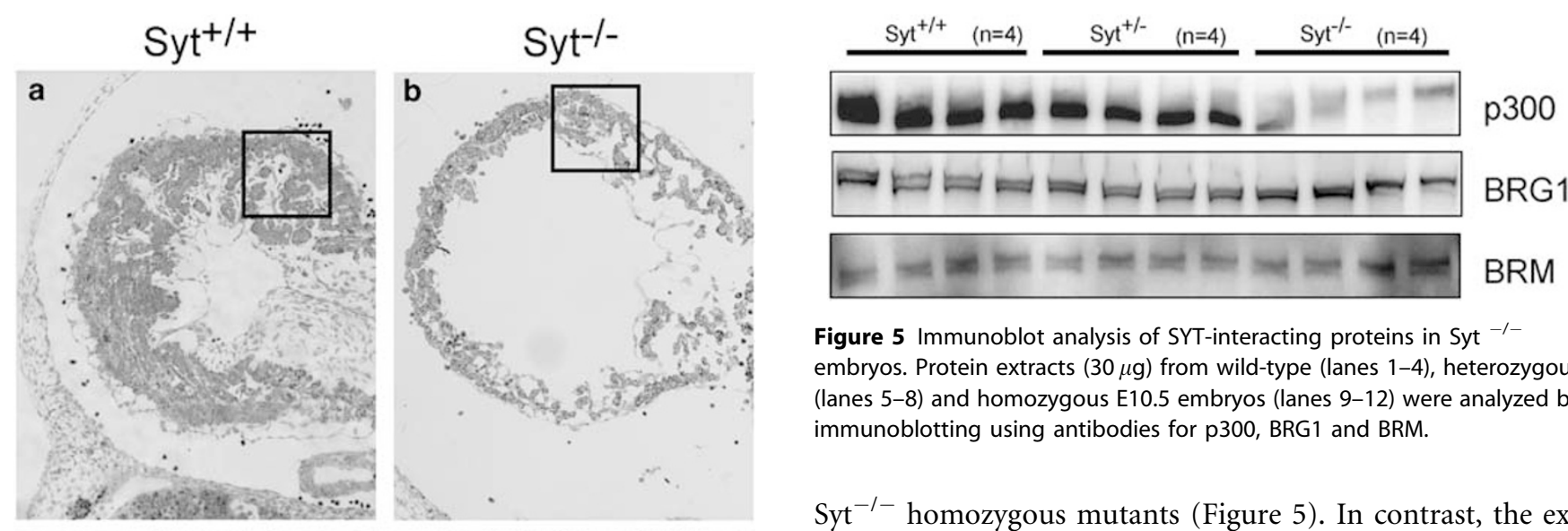

Figure 5 Immunoblot analysis of SYT-interacting proteins in Syt ${ }^{-1}$ embryos. Protein extracts (30 $\mu \mathrm{g})$ from wild-type (lanes 1-4), heterozygous (lanes 5-8) and homozygous E10.5 embryos (lanes 9-12) were analyzed by immunoblotting using antibodies for p300, BRG1 and BRM.
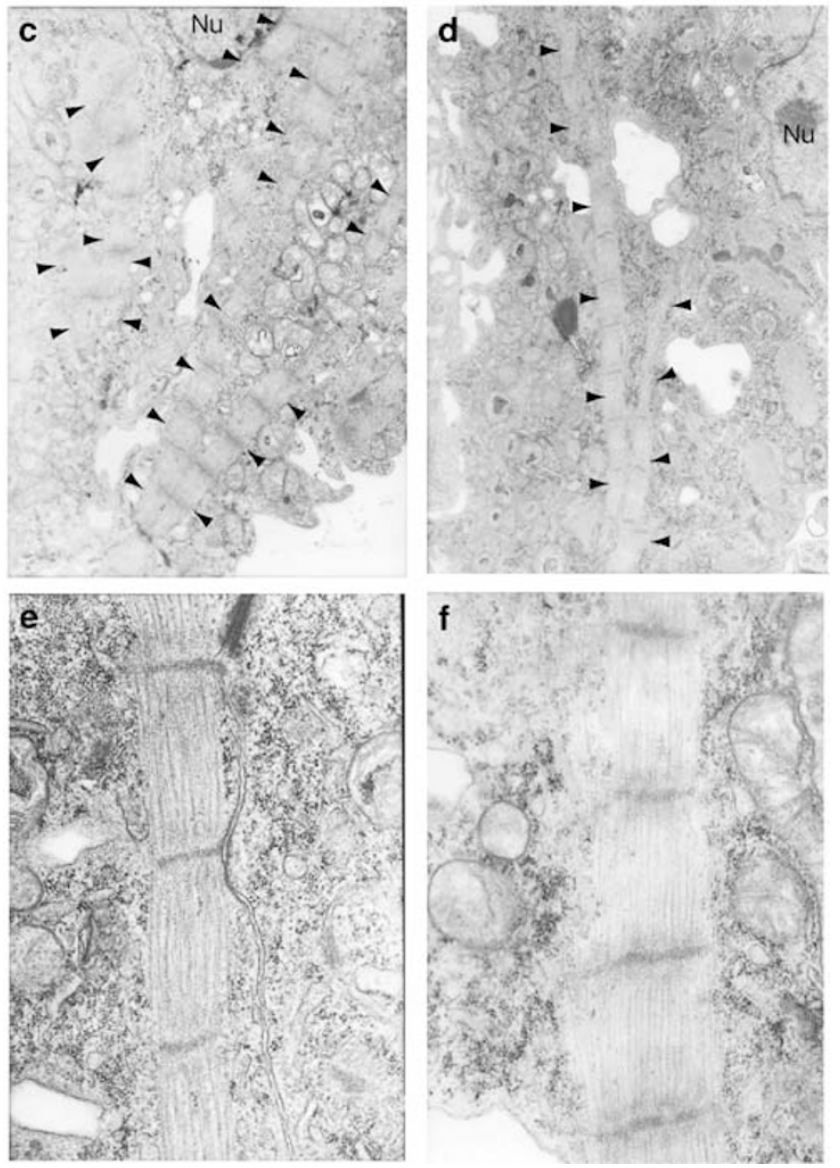

Figure 4 Ultrastructural analysis of embryonic hearts by transmission electron microscopy. (a and $\mathbf{b}$ ) Toluidine blue stain for horizontal section of Syt $^{+/+}$(a) and Syt ${ }^{-1-}$ (b) embryos at E10.5. Squares indicate the areas subjected to EM analysis. (c-f) EM analysis of Syt $+/+(\mathbf{a}, \mathbf{c}$ and $\mathbf{e})$ and $\mathrm{Syt}^{-1-}$ (b, d and f) mutants with magnification $\times 5000$ (c and d) and $\times 100000$ (e and f). Arrowheads in (c) and (d) indicate myofibrils. Nu, nuclei.

We, therefore, analyzed the expression levels of Syt-interacting proteins in $\mathrm{Syt}^{-/-}$embryos, focusing in particular on p300. We performed immunoblot analysis by using lysate of whole embryos of four individual lines of stage-matched $\mathrm{Syt}^{+/+}$, Syt $^{+/-}$and Syt ${ }^{-1-}$ mutants, and found that the expression levels of p300 were significantly decreased in

Syt $^{-1-}$ homozygous mutants (Figure 5). In contrast, the expression levels of BRG1 and hBRM, which are components of SWI/SNF-type chromatin remodeling factors, were not significantly altered between the wild-type and Syt mutant embryos at E10.5 (Figure 5). These results suggest that Syt may regulate the expression level of p300, and the phenotype of the $\mathrm{Syt}^{-1-}$ mutants may reflect at least in part the downregulation of $\mathrm{p} 300$.

\section{Phenotypes of Syt-Deficient Mouse Embryonic Fibroblasts}

To analyse the function of Syt in the cellular level, we established mouse embryonic fibroblasts from wild-type and Syt ${ }^{-1-}$ embryos at E9.75. Interestingly, Syt ${ }^{-1-}$ MEFs were morphologically different from wild-type MEFs (Figure 6a). Wild-type MEFs showed spindle shape, but in contrast, small rounded cells were dominant in $\mathrm{Syt}^{-1-}$ MEFs (Figure 6a, left and right panels). In addition, in confluent culture, Syt ${ }^{-1-}$ MEFs showed sheet cobble stone-like appearance (Figure $6 \mathrm{a}$, center panel).

We next assessed whether Syt affects the formation of actin stress fibers and the localization of paxillin (a major constituent of focal adhesions) by confocal microscopy. Wild-type MEFs exhibited actin stress fiber formation and membrane ruffling; thus cell direction was readily recognized by leading edge (Figure 6b, upper left panel). In addition, localization of paxillin was diffusely observed in the cytoplasm dominantly seen at the ruffling side (Figure 6b, upper center panel).

In contrast, in small round cells, the dominant population in Syt $^{-1-}$ MEFs does not exhibit fine actin fibers but has a dense actin bundle below the plasma membrane (Figure 6b, lower center panel). Paxillin was localized only at the edge of the plasma membrane (Figure 6b, left panel), and we could not recognize directional morphology because of the loss of leading edge. For cell motility assessed by wound closure assay, after $17 \mathrm{~h}$, wild-type MEFs covered most of the wounded area, but Syt $^{-1-}$ MEFs achieved only 35\% (Figure 6c). Thus, Syt plays an important role in the motility of MEFs.

\section{Expression of SYT-Interacting Proteins and Downregulated Gene Expression Profile in Syt ${ }^{-1-}$ MEFs}

To examine the molecular mechanisms of these phenotypes, we analyzed expression levels of Syt-interacting proteins in 
a
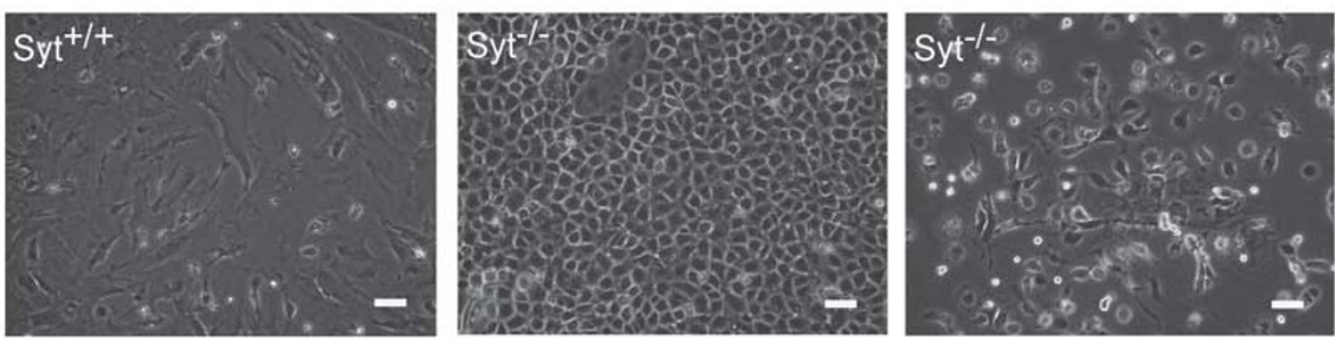

b

Phaloidin

Paxillin
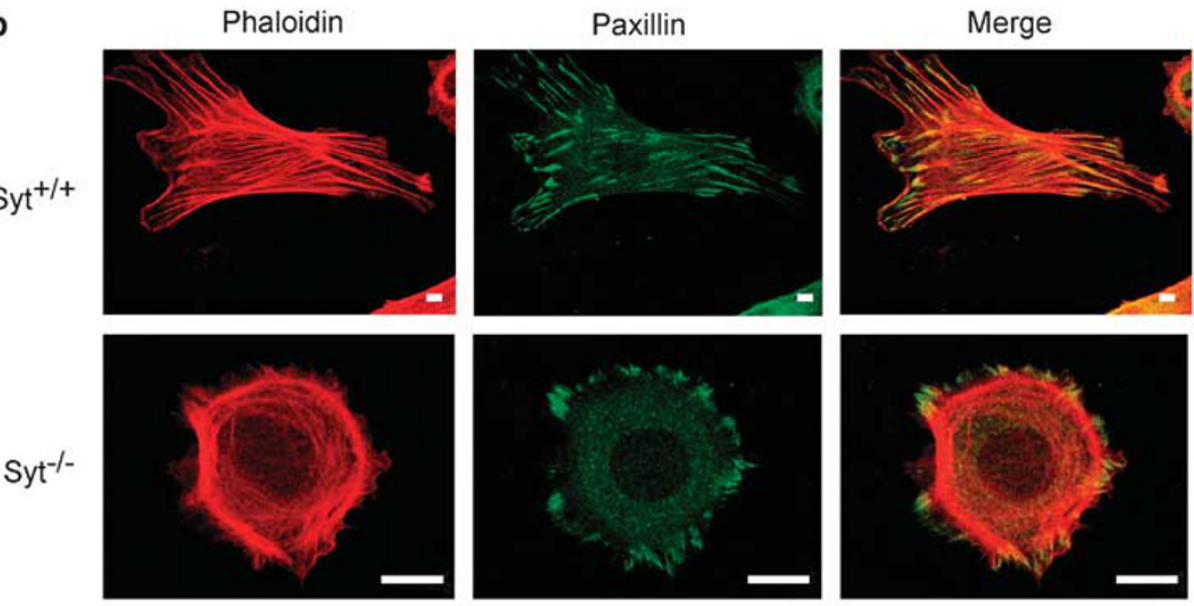

c

Syt $^{+/+}$
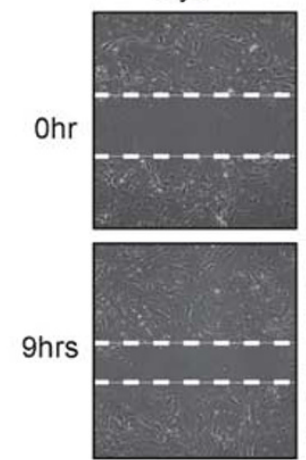

$17 \mathrm{hrs}$

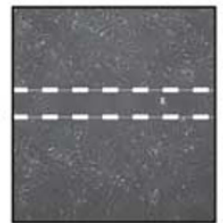

Syt $^{-1-}$
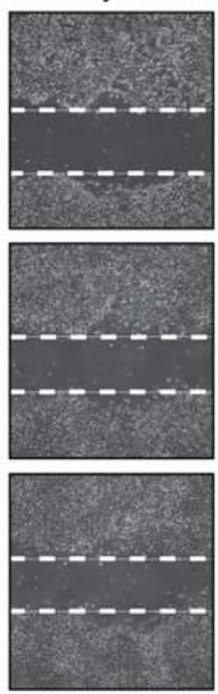

d

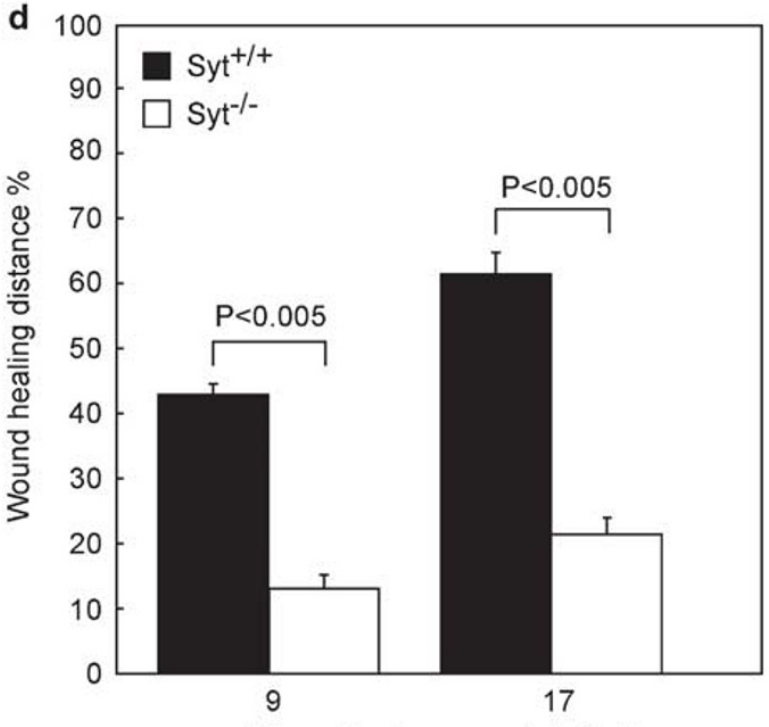

Time after linear scratch (hrs)

Figure 6 Phenotypical analysis of mouse embryonic fibroblasts established from Syt ${ }^{-/-}$embryos at E9.75. (a) Morphology of wild-type MEFs (right panel) and Syt ${ }^{-1-}$ MEFs (center and left panels) in bright field. Scale bars, $50 \mu \mathrm{m}$. (b) Representative micrographs of immunocytofluorescence microscopy. Filamentous actin was visualized by phalloidin (right panels) and focal adhesions were visualized by anti-paxillin (center panels) in wild-type (upper panels) and Syt ${ }^{-1-}$ (lower panels) MEFs, respectively. Scale bars, $10 \mu \mathrm{m}$. (c) Effect of Syt deficiency on motility inhibition. Representative micrographs at the indicated times after wounding. (d) Quantitative data from three independent experiments; columns, means, bars, s.d. (Student's $t$-test).

Syt $^{-1-}$ MEFs, especially focusing on participation of p300 in these phenotypes. We performed immunoblot analysis by using lysate from MEFs of the three individual lines (no. 237, no. 239 and no. 244) established from E9.75 embryos.
Unexpectedly, unlike the result of the whole embryos, the expression level of $\mathrm{p} 300$ did not decrease in Syt ${ }^{-1-}$ MEFs but showed various levels between wild-type and Syt ${ }^{-1-}$ MEFs (Figure 7a). In addition, the expression levels of the other 

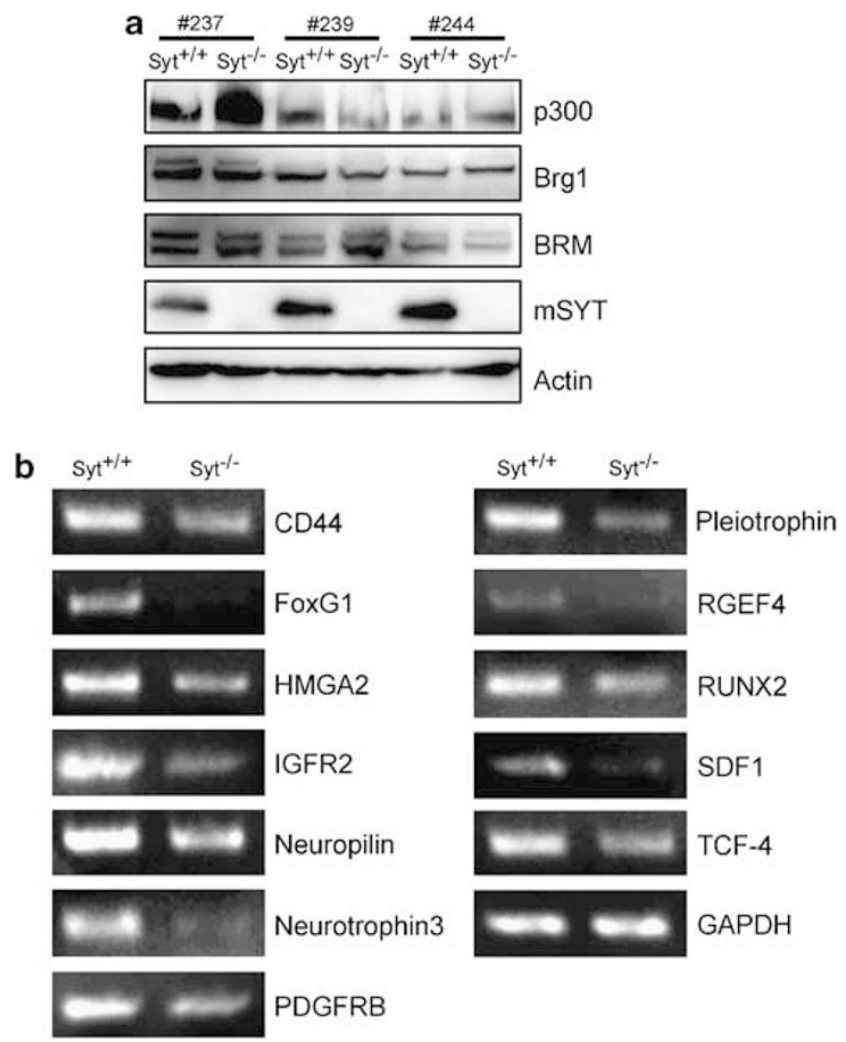

Figure 7 Expression of SYT-interacting proteins and downregulated gene expression in Syt ${ }^{-1-}$ MEFs. (a) Immunoblot analysis of SYT-interacting proteins in Syt ${ }^{-1-}$ MEFs. Three independent lines (no. 237, no. 239 and no. 244 indicate maternal mouse number) of MEFs established from E10.5 embryos of wild-type and Syt ${ }^{-1-}$ were subjected to immunoblot analysis for p300, BRG1, hBRM, SYT and actin and are indicated at the right. Thirty micrograms of proteins were loaded in each lane. (b) Semi-quantitative RT$\mathrm{PCR}$ analysis of gene expression downregulated in Syt ${ }^{-1-}$ MEFs compared with wild type. Representative data of three independent experiments is shown.

Syt-interacting proteins were not significantly altered between wild-type and Syt ${ }^{-1-}$ MEFs (Figure 7a). These data suggest that the expression level of p300 is not essential for the phenotypes of MEFs, at least, in vitro.

To identify the downregulated genes that are related to the phenotypes of $\mathrm{Syt}^{-1-}$ MEFs, we performed Gene Chip analysis using wild-type and Syt ${ }^{-1-}$ MEFs established from embryos at E9.75. Of a total of 22691 genes analyzed, the expression of 2251 genes $(5.41 \%)$ was significantly decreased by a factor of $>3.0$ in $\mathrm{Syt}^{-1-}$ MEFs compared with wild-type MEFs (Table 2). Structural proteins, such as actin or myosin, matrix proteins, such as collagen, adhesion molecules, such as integrin or cadherin, cell surface receptors, such as CD44 or EphA7, and/or signal transducer, such as RGEF4, were downregulated in Syt ${ }^{-1-}$ MEFs. To confirm these observations, we performed semi-quantitative RT-PCR expression analyses of these putative Syt target genes in other three independent sets of MEFs established
Table 2 Selected genes whose expression levels are downregulated in Syt ${ }^{-1-}$ MEFs established from E9.75 embryos compared with wild-type as revealed by Gene Chip analysis

\begin{tabular}{clc}
\hline Accession no. & Gene product & $\begin{array}{c}\text { Fold } \\
\text { change }^{\text {a }}\end{array}$ \\
\hline $\begin{array}{c}\text { Structural matrix } \\
\text { NM_009610 }\end{array}$ & Actin, $\gamma$-2, smooth muscle, enteric & -23.82 \\
NM_013607 & Myosin heavy polypeptide 11, smooth muscle & -20.66 \\
NM_009925 & Procollagen, type X, $\alpha-1$ & -15.77 \\
NM_007733 & Procollagen, type XIX, $\alpha-1$ & -13.96 \\
M12233 & Actin, $\alpha-1$, skeletal muscle & -10.94 \\
NM_007729 & Procollagen, type XI, $\alpha-1$ & -9.18 \\
AW412729 & Procollagen, type XII, $\alpha-1$ & -6.74 \\
AV246911 & Procollagen, type V, $\alpha-1$ & -3.34
\end{tabular}

Transcription factor

$\begin{array}{llr}\text { NM_008241 } & \text { Forkhead box G1 } & -36.50 \\ \text { NM_010791 } & \text { Mesenchyme homeobox 1 } & -22.62 \\ \text { NM_010441 } & \text { High-mobility group AT-hook 2 (Hmga2) } & -11.67 \\ \text { U16321 } & \text { Transcription factor 4 } & -6.14 \\ \text { D14636 } & \text { Runt-related transcription factor 2 (Runx2) } & -3.23\end{array}$

Signal transduction

\begin{tabular}{lll} 
NM_008742 & Neurotrophin 3 & -72.10 \\
NM_008809 & Platelet-derived growth factor receptor, & -54.42 \\
& $\beta$-polypeptide & \\
NM_015814 & Dickkopf homolog 3 (Dkk3) & -29.39 \\
BB623587 & Integrin $\alpha$-8 & -27.47 \\
AB021132 & Rap guanine nucleotide exchange factor 4 & -23.73 \\
NM_008973 & Pleiotrophin & -15.29 \\
BB075797 & Eph receptor A7 & -12.68 \\
NM_008737 & Neuropilin & -6.41 \\
BG066982 & Natriuretic peptide receptor 3 (Npr3) & -4.93 \\
NM_007631 & Cyclin D1 & -4.61 \\
NM_130448 & Protocadherin 18 & -4.41 \\
U04710 & Insulin-like growth factor 2 receptor (lgf2r) & -4.01 \\
BC005676 & CD44 & -3.80 \\
U37029 & Integrin $\beta$-1D & -3.71 \\
NM_021704 & Stromal cell-derived factor 1 & -3.20 \\
NM_011519 & Syndecan 1 & -3.00 \\
\hline & &
\end{tabular}

${ }^{\mathrm{a}}$ Genes are grouped according to the function of the encoded protein. ' - ' indicates the genes whose expression was downregulated in Syt ${ }^{-\prime-}$ MEFs compared with that in wild-type MEFs.

from embryos at E9.75, and the microarray results for all 13 genes downregulated in all Syt ${ }^{-1-}$ MEFs were tested (Figure $7 \mathrm{~b}$ ). 


\section{DISCUSSION}

To understand the biological role of Syt in vivo, we generated Syt-deficient mice and found that Syt deficiency exhibited embryonic lethality, open neural tube and cardiac dysfunction. Syt ${ }^{-1-}$ mutant embryos showed that the defect of ventricular trabeculation and the phenotypes closely resemble those of p300-deficient mice. In fact, the expression levels of p300 were markedly decreased in Syt-deficient mice. Moreover, we isolated $\mathrm{Syt}^{-1-}$ MEFs to elucidate the cellular basis of abnormalities in Syt-deficient embryos and showed that Syt participates in the regulation of actin fiber and cell motility.

While this work was in progress, another group reported the establishment of Syt-deficient mice, and they reported that Syt deficiency was lethal either through incomplete chorio-allantoic fusion or through a defect in the subsequent process of vascular branching morphogenesis. ${ }^{17}$ Surprisingly, placental defect was rarely seen in our Syt ${ }^{-1-}$ mutant embryos. The reason for this discrepancy is not clear, but may be due to differences in targeting strategies or in the genetic background of mice because of using different ES cells.

Syt was found to be essential for early embryogenesis and does not share functional redundancy with other proteins at least in the embryonic stage. In addition, Syt ${ }^{+/-}$heterozygous mutants showed haplo-insufficient lethality, which is a relatively rare phenotype in gene-disrupted mice. To our knowledge, haplo-insufficient lethality has been observed for p300, Dll4, Vezf1 and ROCK1. ${ }^{19-21}$ During embryogenesis, the dosage of Syt may be critical for survival in a certain period in utero because newborn Syt ${ }^{+/-}$mutants lack overt defects. Once such Syt ${ }^{+/-}$embryos have completed gestation, the reduced Syt dosage does not seem to influence the growth of the newborns.

Normal placental development is initiated by the fusion of the chorionic and allantoic membranes (chorio-allantoic fusion) at E8.5 (8 somites), ${ }^{22-24}$ thereby forming the chorionic plate, which is composed of trophoblasts. Through a subsequent process of vascular branching, fetal and maternal blood vessels enter this layer at E9.0, including the development of the placental labyrinth layer, which is made up of syncytiotrophoblasts, and at E10.0, the placenta becomes fully functional. The mutant mice in which the placenta is the only defective organ generally die no sooner than E9.5. In our mutant mice, the major defect begins before E8.5 at least, prior to the usual time of placental lethality. These data suggest that the main reason for our Syt ${ }^{-1-}$ mutant's lethality was not likely to be the placental defect.

Although, morphologically, Syt ${ }^{-1-}$ embryo displayed cardiac abnormalities, the expression levels of genes being essential for cardiac development, including GATA4, MEF2C, Nkx2.5 and so on, ${ }^{25}$ were not decreased in $\mathrm{Syt}^{-1-}$ embryos. As the proportion of cardiogenesis-specific transcription factor transcripts is very small compared with total embryo mRNA, the difference between wild-type and mutant embryos may not be detectable by this approach.
Interestingly, these embryonic neural and cardiac phenotypes of Syt ${ }^{-l-}$ embryos closely resemble those of p300-deficient mice. ${ }^{18}$ On the basis of our data showing that protein levels of p300 were decreased in $\mathrm{Syt}^{-1-}$ embryos, Syt may regulate cardiac ventricular maturation through the control of p300 expression.

It was also reported that the SWI/SNF type of chromatin remodeling complex, such as BAF60c and BAF180, has been shown to be required for cardiogenesis. ${ }^{26,27}$ In fact, we have found that Syt binds to the complete BAF complex by MALDI-TOF mass spectrometry ( $\mathrm{T}$ Kimura, unpublished data). Thus, in the absence of Syt, the deregulation of BRG1 together with p300 possibly underlies the defects in the proteins closely related to myofibril formation.

Syt-deficient cells with actin fiber deregulation and suppressed motility might explain the developmental problem. One possible mechanism is that complex formation of SYT and p300, and not only the amount of p300, may regulate cell motility. It was reported that SYT/p300 complex promotes cell adhesion by regulating $\beta 1$ integrin/fibronectin receptor function. ${ }^{11}$ In fact, our Gene Chip analysis showed that integrin $\beta 1 \mathrm{D}$ and integrin $\alpha 8$, which form heterodimeric transmembrane receptor for fibronectin, ${ }^{28}$ were downregulated in $\mathrm{Syt}^{-1-}$ MEFs. Thus, p300/SYT complex possibly regulates cell motility through the $\beta 1$ integrin and/or $\alpha 8$ integrin.

Alternatively, Syt regulated cell migration through the transcriptional regulation of Rap guanine nucleotide exchange factor 4 (now designated as Epac2), which is one of the decreased genes in Syt ${ }^{-1-}$ MEFs. Epac2 was initially characterized as a cAMP-activated GEF for Rap1 and Rap2, ${ }^{29,30}$ and as a novel sensor for several pivotal cellular processes, including cell polarization, integrin-mediated cell adhesion, cell migration and cytoskeletal rearrangements through the regulation of Rap, Rho, Ras and Rac. ${ }^{31-34}$ As such, we think the possibility that Syt regulates Ras and Rho superfamily through the transcriptional regulation of Epac2.

In this study, we discovered new phenotypes of Syt, such as poor ventricular trabeculation and downregulation of p300 protein in $\mathrm{Syt}^{-1-}$ whole embryos. In addition, by the establishment of Syt ${ }^{-/-}$MEFs, we uncovered that Syt plays an important role in the regulation of cell motility. Thus, Syt ${ }^{-1-}$ MEFs must be one of the useful materials to analyze Syt functions in detail. In future, we will study the association between Syt and malignant human cancer such as synovial sarcoma.

Supplementary Information accompanies the paper on the Laboratory Investigation website (http://www.laboratoryinvestigation.org)

\section{ACKNOWLEDGEMENTS}

We thank Dr Ken Sasai (Hokkaido University) and Hiroaki Hiraga (Sapporo Cancer (enter) for useful suggestions. This study was supported in part by grants-in-aid from the Ministry of Education, Science, Culture, and Sports, and from the Ministry of Health, Labor, and Welfare; and also by the 
YASUDA Medical Research Foundation, by the Suhara Foundation, by the Mochida Memorial Foundation for Medical and Pharmaceutical Research and by the UEHARA Medical Research Foundation.

1. Ladanyi M. Fusions of the SYT and SSX genes in synovial sarcoma. Oncogene 2001;20:5755-5762.

2. Lewis JJ, Antonescu CR, Leung $\mathrm{DH}$, et al. Synovial sarcoma: a multivariate analysis of prognostic factors in 112 patients with primary localized tumors of the extremity. J Clin Oncol 2000;18:2087-2094.

3. Clark J, Rocques PJ, Crew AJ, et al. Identification of novel genes, SYT and SSX, involved in the $\mathrm{t}(\mathrm{X} ; 18)(\mathrm{p} 11.2 ; \mathrm{q} 11.2)$ translocation found in human synovial sarcoma. Nat Genet 1994;7:502-508.

4. dos Santos NR, de Bruijn DR, van Kessel AG. Molecular mechanisms underlying human synovial sarcoma development. Genes Chromosomes Cancer 2001;30:1-14.

5. Thaete $C$, Brett $D$, Monaghan $P$, et al. Functional domains of the SYT and SYT-SSX synovial sarcoma translocation proteins and colocalization with the SNF protein BRM in the nucleus. Hum Mol Genet 1999;8:585-591.

6. Brett $D$, Whitehouse $S$, Antonson $P$, et al. The SYT protein involved in the $t(X ; 18)$ synovial sarcoma translocation is a transcriptional activator localized in nuclear bodies. Hum Mol Genet 1997;6:1559-1564.

7. Nagai $M$, Tanaka $S$, Tsuda $M$, et al. Analysis of transforming activity of human synovial sarcoma-associated chimeric protein SYT-SSX1 bound to chromatin remodeling factor hBRM/hSNF2 alpha. Proc Natl Acad Sci USA 2001:98:3843-3848.

8. Kato $\mathrm{H}$, Tjernberg $\mathrm{A}$, Zhang W, et al. SYT associates with human SNF/ SWI complexes and the C-terminal region of its fusion partner SSX1 targets histones. J Biol Chem 2002;277:5498-5505.

9. Ishida $\mathrm{M}$, Tanaka $\mathrm{S}$, Ohki $\mathrm{M}$, et al. Transcriptional co-activator activity of SYT is negatively regulated by BRM and Brg1. Genes Cells 2004;9:419-428.

10. de Bruijn DR, dos Santos NR, Thijssen J, et al. The synovial sarcoma associated protein SYT interacts with the acute leukemia associated protein AF10. Oncogene 2001;20:3281-3289.

11. Eid JE, Kung AL, Scully R, et al. p300 interacts with the nuclear protooncoprotein SYT as part of the active control of cell adhesion. Cell 2000;102:839-848.

12. Ito $T$, Ouchida M, Ito $S$, et al. SYT, a partner of SYT-SSX oncoprotein in synovial sarcomas, interacts with $\mathrm{mSin} 3 \mathrm{~A}$, a component of histone deacetylase complex. Lab Invest 2004;84:1484-1490.

13. Nakayama K, Ishida N, Shirane M, et al. Mice lacking p27(Kip1) display increased body size, multiple organ hyperplasia, retinal dysplasia, and pituitary tumors. Cell 1996;85:707-720.

14. Sambrook J, Maniatis T, Fritsch EF. Molecular Cloning. A Laboratory Manual, 2nd edn. Cold Spring Harbor Laboratory: NY, 1989.

15. Yang JT, Rayburn $\mathrm{H}$, Hynes RO. Embryonic mesodermal defects in $\alpha 5$ integrin-deficient mice. Development 1993;119:1093-1105.

16. Defilippi $P$, Truffa $G$, Stefanuto $G$, et al. Tumor necrosis factor a and interferon g modulate the expression of the vitronectin receptor (integrin h3) in human endothelial cells. J Biol Chem 1991;266: 7638-7645.
17. de Bruijn DR, Peters WJ, Chuva de Sousa Lopes SM, et al. Targeted disruption of the synovial sarcoma-associated SS18 gene causes early embryonic lethality and affects PPARBP expression. Hum Mol Genet 2006;15:2936-2944.

18. Yao TP, Oh SP, Fuchs M, et al. Gene dosage-dependent embryonic development and proliferation defects in mice lacking the transcriptional integrator p300. Cell 1998;93:361-372.

19. Gale NW, Dominguez MG, Noguera I, et al. Haploinsufficiency of deltalike 4 ligand results in embryonic lethality due to major defects in arterial and vascular development. Proc Natl Acad Sci USA 2004;101:15949-15954.

20. Kuhnert F, Campagnolo L, Xiong JW, et al. Dosage-dependent requirement for mouse Vezf1 in vascular system development. Dev Biol 2005;283:140-156.

21. Zhang YM, Bo J, Taffet GE, et al. Targeted deletion of ROCK1 protects the heart against pressure overload by inhibiting reactive fibrosis. FASEB J 2006;20:916-925

22. Cross JC. Genetic insights into trophoblast differentiation and placental morphogenesis. Semin Cell Dev Biol 2000;11:105-113.

23. Rossant J, Cross JC. Placental development: lessons from mouse mutants. Nat Rev Genet 2001;2:538-548.

24. Hemberger M, Cross JC. Genes governing placental development. Trends Endocrinol Metab 2001;12:162-168.

25. Srivastava D, Olson EN. A genetic blueprint for cardiac development. Nature 2000;407:221-226.

26. Lickert H, Takeuchi JK, Von Both I, et al. Baf60c is essential for function of BAF chromatin remodelling complexes in heart development. Nature 2004;432:107-112.

27. Wang Z, Zhai W, Richardson JA, et al. Polybromo protein BAF180 functions in mammalian cardiac chamber maturation. Genes Dev 2004;18:3106-3116.

28. Brakebusch C, Fassler R. $\beta 1$ integrin function in vivo: adhesion, migration and more. Cancer Metastasis Rev 2005;23:403-411.

29. de Rooij J, Zwartkruis FJ, Verheijen MH, et al. Epac is a Rap1 guanine nucleotide-exchange factor directly activated by cyclic AMP. Nature 1998;396:474-477.

30. Kawasaki H, Springett GM, Mochizuki N, et al. A family of cAMP-binding proteins that directly activate Rap1. Science 1998;282:2275-2279.

31. Bos JL. Linking Rap to cell adhesion. Curr Opin Cell Bio 2005;17: 123-128.

32. Gupta M, Yarwood SJ. MAP1A light chain 2 interacts with exchange protein activated by cyclic AMP 1 (EPAC1) to enhance Rap1 GTPase activity and cell adhesion. J Biol Chem 2005;280: 8109-8116.

33. Del Pozo MA, Alderson NB, Kiosses WB, et al. Integrins regulate Rac targeting by internalization of membrane domains. Science 2004;303:839-842.

34. Rangarajan S, Enserink JM, Kuiperij HB, et al. Cyclic AMP induces integrin-mediated cell adhesion through Epac and Rap1 upon stimulation of the beta 2-adrenergic receptor. J Cell Biol 2003;160: 487-493. 